\title{
Os desafios da produção de conhecimento em Administração no Brasil
}

\author{
The challenges of Management knowledge production in Brazil
}

\author{
Carlos Osmar Bertero ${ }^{2}$ \\ Rafael Alcadipani ${ }^{3}$ \\ Sandro Cabral ${ }^{4}$ \\ Alexandre Faria ${ }^{5}$ \\ Luciano Rossoni ${ }^{6}$
}

Apresentação

Carlos Osmar Bertero

Foi motivo de satisfação poder apresentar aos participantes do Encontro da Anpad, em setembro de 2012, e também agora, aos leitores dos Cadernos EBAPE.BR, o texto que resume o que foi exposto no encontro pelos colegas participantes do painel. $\mathrm{O}$ assunto de interesse permanente em nossa comunidade científica são os rumos e problemas da produção de conhecimento em Administração em nosso país nos dias atuais.

Devido à liberdade conferida aos participantes para que expusessem suas ideias, o resultado foi que cada um optou por apresentar o que lhe parecesse mais relevante e, felizmente, nenhum deles hesitou em manifestar seus valores. $\mathrm{O}$ resultado foram relatos interessantes, mas que não poderiam ser consolidados em um texto

Texto submetido em 30 de outubro de 2012 e aceito para publicação em 07 de março de 2013.

${ }^{1}$ Gostaríamos de agradecer à Profa. Ana Guedes, ex-editora do Cadernos EBAPE.BR, por ter pautado este artigo e dando grande incentivo para a sua realização.

2 Doutor em Administração pela Cornell University; Professor Titular da Fundação Getulio Vargas / Escola de Administração de Empresas de São Paulo. Endereço: Avenida Nove de Julho, 2029, CEP 01313-920, São Paulo - SP, Brasil. E-mail: carlos.bertero@fgv.br

${ }^{3} \mathrm{PhD}$ in Business Administration pela Manchester Business School; Professor Adjunto da Fundação Getulio Vargas / Escola de Administração de Empresas de São Paulo. Endereço: Avenida Nove de Julho, 2029, CEP 01313-920, São Paulo - SP, Brasil. Email: Rafael.Alcadipani@fgv.br

${ }^{4}$ Doutor em Administração pela UFBA; Professor Adjunto III da Escola de Administração da UFBA. Endereço. Av. Reitor Miguel Calmon, s/n, 3.andar, Vale do Canela, CEP 40110-903, Salvador - BA, Brasil. E-mail: scabral@ufba.br

${ }^{5} \mathrm{PhD}$ em Industrial and Business Studies pela University of Warwick, UK; Professor Adjunto da Fundação Getulio Vargas. Endereço: FGV/EBAPE - Escola Brasileira de Administração Pública e de Empresas, Praia de Botafogo, 190 - 4ํ e 5 andares, Botafogo, CEP 22253-900, Rio de Janeiro - RJ, Brasil. E-mail: alex.faria@fgv.br

${ }^{6}$ Doutor em Administração pela UFPR; Professor do Programa de Pós-Graduação em Administração da UNIGRANRIO. Endereço: Ppga Unigranrio - Rua da Lapa, 86, $9^{\circ}$ andar, Centro, CEP 22220-040, Rio de Janeiro, RJ, Brasil. E-mail: Irossoni@gmail.com 
único que fosse conjuntamente firmado. Assim, optou-se por preservar integralmente os relatos apresentados por cada um, e eu, como apresentador, limitar-me-ei a redigir as considerações gerais.

Não posso fugir à tentação de generalizar, mesmo diante de relatos tão diferentes. E a generalização que me ocorre a partir dos relatos de Rafael Alcadipani, Sandro Cabral, Alexandre Faria e Luciano Rossoni é que, após 513 anos, ser brasileiro ainda constitui uma dificuldade. Sandro reconhece as inegáveis dificuldades para publicar internacionalmente, e não necessariamente devido a problemas de qualidade do material apresentado, mas, muitas vezes, por preconceito e pelo fato de que não somos pessoas bem situadas e implicitamente avaliadas pelos periódicos internacionais de maior prestígio e pontuação, inteligivelmente situados no mainstream. Entretanto, ao fim e ao cabo, Sandro aceita o desafio de enfrentar o mundo e plantar nossa produção lá fora. Já Rafael e Alexandre são mais reticentes. Ambos apresentam mais críticas e restrições ao cenário internacional, embora sejam diferentes. Rafael pareceu-me mais focado em criticar o predomínio do mainstream anglo-saxão nos conselhos editoriais e, consequentemente, entre os avaliadores. Já Alexandre tece crítica bem mais profunda e substantiva, na medida em que introduz elemento geopolítico em sua análise. Sua intervenção nos coloca diante de uma literatura pouco conhecida entre nós, brasileiros, sobre a geopolítica do conhecimento e, por esse caminho, acaba por encontrar algumas pontes com Rafael na temática do colonialismo ou neocolonialismo.

A colocação de Alexandre é oportuna porque situa o debate em um mundo ampliado e em brusca transformação. Todos reconhecem que a ordem mundial se altera rapidamente. Que vivemos um momento de transformações que serão decisivas para a humanidade. Não se trata de retomar o velho tema da "decadência do Ocidente" euro-americano. Certamente, não há e não deverá haver decadência, mas emergem outros focos de poder e isso levará a um reordenamento mundial. Alexandre nos lembra de um longo arco colonial, iniciado pelos europeus no século XV e que se estendeu até o final da Segunda Guerra Mundial. O encerramento formal dos impérios coloniais europeus não necessariamente extinguiu o colonialismo e a colonialidade. A intervenção de Alexandre, apoiada no referencial teórico de Walter Mignolo, desafia-nos a pensar como ficariam nossas pesquisas diante dessa reviravolta geopolítica. Ele não desce a detalhes, mas tenta investigar como isso seria trocado nos miúdos de projetos e linhas de pesquisa, se seria uma proposta interessante a ser explorada.

As colocações de Rafael sobre estrangeirismo, paroquialismo e produtivismo apresentam, paradoxalmente, um quadro que me pareceu equilibrado. Os três inconvenientes, observáveis em nossa comunidade científica brasileira de Administração, seriam, necessariamente, o resultado de um desequilíbrio. O produtivismo é a atitude desequilibrada na qual a qualidade, a pertinência e os padrões éticos cederiam ao imperativo de pontuações e CVs recheados de títulos. É sempre oportuno lembrar que as grandes e marcantes obras de nossa área não seriam possíveis em regime produtivista. Aqui, cabe a observação de Luciano Rossoni de que os padrões Capes/CNPq não seriam as únicas explicações para a adoção de uma atitude e comportamentos produtivistas. Haveria algo mais profundo para que nos tornássemos produtores produtivistas de conhecimento. É interessante aprofundar essa reflexão e ver quais seriam esses motivos. O paroquialismo, que eu também denominaria provincianismo, é uma longa tradição brasileira. Já Gregório de Matos, no século XVII, lembrava que os cá nascidos tendiam a achar tudo daqui melhor do que aquilo existente em Portugal. Daí ao verde de nossas matas, ao azul de nossos céus, ao fulgor de nossas estrelas foi um passo dado pelos diversos ufanistas do século XIX. Talvez estejamos a fazer coisa parecida com alguns autores nacionais. O provincianismo, ou paroquialismo, é uma atitude desequilibrada na avaliação de autores, de teorias e da produção científica em geral, que acabam sendo sobreapreciados pelo fato de ser nacionais. $\mathrm{O}$ contracanto administrativista do paroquialismo é a rejeição de algo por não ter sido desenvolvido aqui (not invented here). Finalmente, o mais frequente problema seria o estrangeirismo, que é clara manifestação de sentimento de inferioridade. É, certamente, o mais encontradiço em nossa produção e em nosso comportamento. O desequilíbrio do estrangeirismo seria a sobrevalorização do que é estrangeiro pelo simples fato de ser estrangeiro e isso traz implícita a colocação de que somos inferiores. A literatura que 
avalia e critica nossa produção científica tem apontado com frequência o que Rafael designou como estrangeirismo.

O texto de Luciano Rossoni é confessadamente neoinstitucionalista, mas não necessariamente acrítico. Nossa comunidade, aplicando etiquetas a autores e teorias com frequência, costuma alinhar o institucionalismo a posições conservadoras e, necessariamente, ligadas ao mainstream anglo-saxão. Diferentemente, o texto de Luciano acaba por aceitar muitos elementos que constituem pontos fundamentais da epistemologia e da filosofia da ciência em nossos dias. Dentre eles o reconhecimento de que todo conhecimento é relativo e que a falibilidade de teorias e metodologias faz parte da realidade. Aceita, em boa medida, as restrições críticas feitas por Rafael Alcadipani e, igualmente, as ponderações críticas e demandadoras de mudanças de Alexandre Faria. Embora o texto de Luciano peça licença para ser normativo apenas em seu último parágrafo, eu o achei normativo por inteiro. Lembra-nos oportunamente a colocação clássica de Robert Merton sobre o que deve ser o conhecimento universal, comunal (communalism), desinteressado e ceticamente organizado. Como esses termos, para Merton, tem um significado que não é geralmente conhecido, permito-me, aqui, fazer algumas ponderações. O universalismo do conhecimento proposto por Merton não é o da tradição filosófica ocidental que vem de Platão até o final do século XIX, no qual universalidade dizia respeito ao caráter geral e à capacidade de oferecer uma explicação exaustiva da realidade. Tradicionalmente, o universalismo também serviria para que o conhecimento fosse atemporal. Não são esses os sentidos que Merton dá ao universalismo, mas ele atribui a este a eliminação de qualquer atitude preconceituosa envolvendo questões étnicas, ideologias, gênero etc. O caráter comunal torna o conhecimento um patrimônio de todos, de toda a comunidade, e, portanto, nada tem a ver com restrições de natureza proprietária. $\mathrm{O}$ conhecimento torna-se, necessariamente, um patrimônio de todos. $\mathrm{O}$ caráter do conhecimento como sendo desinteressado, nos dias atuais, é mais controvertido. Merton diz que o desinteresse implica qualquer deslize que, por razões de interesses os mais diversos do pesquisador ou teórico, venha a influenciar o trabalho científico por fatores que não sejam estritamente os ditados pelo próprio trabalho científico. Isso chega quase ao limiar de dizer que o conhecimento deve ser value-free, o que é, hoje, uma afirmação de difícil e problemática aceitação. E, finalmente, temos o ceticismo organizado. Embora, aqui, a terminologia mertoniana possa parecer estranha, parece-me querer dizer que o conhecimento deve ser, necessariamente, crítico e que deve adotar procedimentos metodológicos rigorosos, sendo submetido à comunidade científica para ser amplamente criticado. Apenas depois de passar por esse teste é que o conhecimento, de alguma maneira, tornar-se-ia legítimo.

Os quatro colegas do painel apresentaram perspectivas diferentes, contraditórias entre si, por vezes com certeza, mas que trouxeram aos que estavam presentes no evento, e, agora, ao leitor, ideias, sugestões e críticas dignas de reflexão e que permitem afirmar que o painel não terminou quando se esgotou o tempo que lhe havia sido concedido na agenda do evento e que não termina com a leitura deste texto. Minha recomendação ao leitor é que aceite os desafios à reflexão aqui contidos e que isso venha a influenciar positivamente seus trabalhos científicos.

Os Desafios da Academia Brasileira em Administração enquanto Empreendimento Social

Luciano Rossoni

Reservar uma discussão acerca dos problemas da pesquisa em Administração brasileira é tarefa deveras difícil, também severa, especialmente quando ela é realizada por indivíduos que a produzem. Isso porque o risco de cair na demagogia ou simplesmente na parcialidade é alto, pois estamos analisando, e até criticando, práticas as quais nós, muitas vezes, reproduzimos. No entanto, por mais desafiadora que seja essa tarefa, e 
por mais que fiquemos expostos a ela, acredito que toda reflexão sobre nosso dia a dia como pesquisadores seja pertinente, pois ajuda a revelar o quanto ainda temos de progredir enquanto comunidade acadêmica.

Por essas razões, com o objetivo de criticar nosso trabalho enquanto pesquisadores, tentarei ser coerente com o quadro analítico que adotei nos últimos anos, que é o institucionalismo sociológico e organizacional. Com isso, pretendo, ao mesmo tempo, ser fiel à crença de que a academia também deve ser objeto de análise das teorias por ela formuladas, tal como buscarei reduzir a possibilidade de ser parcial ou injusto em meus argumentos. Para tanto, primeiramente, defenderei a tese de que a academia deve ser vista como empreendimento social imerso em outros sistemas da atividade humana. Em segundo lugar, considerando essa tese, discutirei alguns problemas levantados pelos demais colegas, que envolvem produtivismo, paroquialismo, estrangeirismo e colonialismo. Por fim, em um tom mais normativo, apelo à necessidade de discutir os princípios pelos quais nossas atividades acadêmicas são construídas, dando destaque, em especial, à necessidade de pensar a crítica aberta entre pares como critério de demarcação da atividade científica.

\section{A academia enquanto sistema social}

Apesar das várias definições existentes do que seria a ciência e a academia, é inegável que qualquer ideia contemporânea sobre ambas reconheçam que elas sejam um empreendimento social. Para fins didáticos, podemos dividi-lo em três facetas ${ }^{7}$.

A primeira faceta envolve o conteúdo propriamente dito da ciência. Faz parte dessa faceta o conjunto de teorias e seus respectivos conceitos que utilizamos para apreender a realidade, assim como qualquer estoque de conhecimento acessório e necessário, inclusive o burocrático, para que o trabalho do pesquisador seja realizado. Em especial, também compõem essa faceta os métodos, as técnicas e os instrumentos que utilizamos para dar credibilidade aos meios pelos quais alcançamos nosso resultado.

A segunda faceta, de caráter mais diverso, compreende as relações sociais nas quais os pesquisadores estão imersos, caracterizadas por atores individuais e coletivos estratificadamente posicionados no campo, assim como seus respectivos papéis sociais. No nível individual podemos citar, por exemplo, algumas dessas posições: alunos, professores, pesquisadores, líderes de tema, áreas e associações, editores e conselheiros de periódicos e representantes de área. No nível coletivo podemos pensar em grupos de pesquisa, redes de pesquisadores, programas de pós-graduação, periódicos, bases de dados, instituições de ensino e pesquisa, associações de área, órgãos de fomento e reguladores, entre outros.

Além dessa listagem, temos de considerar que vários atores sociais hipoteticamente fora do sistema da ciência exercem influência sobre ele, em especial o governo e a sociedade na qual a ciência está imersa. Como a história demonstra, recursos são direcionados a partir daquilo que é considerado socialmente válido ou até por estar de acordo com interesses governamentais. Ademais, muitas vezes, os problemas de natureza científica considerados legítimos nada têm a ver com a contribuição para o conhecimento, mas sim com a aplicabilidade ou com o apelo para o grande público.

Por fim, a terceira faceta envolve o aparato institucional da ciência, incluindo suas crenças, valores, normas e pressupostos que definem aqueles fins desejados por um grupo de pesquisadores, tais como os meios pelos quais eles podem ser alcançados de forma legítima. Incluem-se nessa faceta as normas e os parâmetros a

${ }^{7}$ Ideias de ciência similares à desenvolvida aqui podem ser observadas em Kuhn (2009), quando o autor trata dos paradigmas da ciência; em Lakatos (1978), acerca dos programas de investigação científica; e em Merton (1996), no que se refere à ciência enquanto instituição. 
partir dos quais o conteúdo de artigos e livros é julgado pelos pares como válido, assim como quais periódicos devem obter maior reconhecimento. Adicionalmente, é nessa faceta que se consolidam os mecanismos de recompensa e punição que, plausivelmente, estratificam os autores em termos de mérito e competência, tal como os critérios segundo os quais eles estão habilitados a fazer parte da comunidade.

Em muitos casos, essas crenças e valores podem ser postulados como imperativos, como, por exemplo, em Merton (1996), na discussão sobre o éthos da ciência. Para o autor, a ciência moderna encontra-se pautada em quatro cânones: (1) universalismo, postulando que o desejo da ciência de aproximar-se da verdade deve ser realizado tendo em vista critérios impessoais, desconsiderando qualquer aspecto pejorativo, entre eles distinções entre gênero, etnia, classe social, cor ou qualquer outro atributo individual ou social; (2) comunalismo, que caracteriza os resultados da ciência como bem coletivo, no qual suas descobertas são de utilidade comum, cabendo ao pesquisador somente o reconhecimento pelo seu trabalho; (3) desinteresse, que reprova qualquer prática ou interesse do pesquisador na produção do conhecimento que coloque em suspeita a integridade do seu trabalho; (4) ceticismo organizado, que enfatiza que as ideias devem, necessariamente, passar pelo rigoroso escrutínio da comunidade acadêmica, sendo consideradas verdadeiras somente depois de aceitas como lógicas ou empiricamente válidas.

Essas três facetas são interdependentes e, no caso da última, pode-se notar que muito do que a caracteriza envolve princípios e ideais que não são, necessariamente, compartilhados por toda a academia. Entretanto, como destacarei adiante, alguns dos problemas que apresentamos na pesquisa em Administração no Brasil (e não somente aqui e na Administração) estão, aparentemente, relacionados à pequena energia que nossa comunidade gasta para definir quais seriam os critérios socialmente válidos de nossa atividade.

\section{Desafios recorrentes da academia brasileira em Administração (e não somente dela)}

O primeiro dos problemas que os demais colegas do fórum destacaram, que também já foi debatido em vários artigos de nossa área, envolve o desejo insaciável de publicar artigos em periódicos e de apresentar papers em eventos acadêmicos. Muitos atribuem as causas desse comportamento à política de avaliação da Capes. No entanto, a meu ver, aceitar uma explicação como essa soa, por exemplo, nas devidas proporções, como atribuir toda criminalidade à falta de punição. Não significa que estamos negando que os critérios atuais possam levar a uma interpretação de que publicar mais é melhor, mas atribuir somente às regras essa causa é uma solução demasiadamente simplista para o problema. Sendo assim, tendo em mente alguns dos cânones que apontei, cabe questionar o que é mais valioso: publicar muito ou desenvolver estudos que possam contribuir com o avanço do conhecimento na área? Além disso, devemos revisar os meios pelos quais esses estudos são produzidos. Não é nada incomum ver pesquisadores de nossa área ser coautores de artigos, em especial de alunos, com mínima ou nenhuma contribuição, fazendo-o simplesmente para alcançar mais pontos no sistema de avaliação. Além de injusta, imoral e desonesta, tal prática corrompe nosso sistema de avaliação, empurrando cada vez mais as exigências de pontuação para cima. Em suma, não é só a pontuação da Capes como meta que desvirtua nossa almejada produção, mas, também, o modo como atingimos esses pontos.

O segundo problema remete ao cada vez mais necessário, mas também polêmico, objetivo de internacionalizar nossa produção. Como alguns podem notar, é comum em aulas magnas dos programas de pós-graduação, assim como em debates em nossas associações, que a internacionalização é uma meta da academia em Administração. Independentemente da importância de tal tema, temos de ter em mente que, assim como na produção de artigos, devemos questionar com quanto estamos contribuindo localmente com a academia quando produzimos lá fora e com quanto estamos repercutindo em termos de qualidade no fórum global. Em muitos casos, a questão da internacionalização tem gerado preconceitos nos quais boa parte da 
explicação de sua necessidade é pautada na mera retórica de que internacionalizar é bom porque é bom internacionalizar.

Tendo em vista a minha fala, alguns podem acreditar que sou contra a internacionalização da produção brasileira em Administração, mas, como vários colegas que vêm produzindo lá fora apontaram, nossa produção ainda sofre preconceito nos fóruns internacionais em que competimos desigualmente com players globais. Como os colegas Alexandre Faria, Rafael Alcadipani e Sandro Cabral têm apontado, sofremos com o colonialismo acadêmico, no qual aqueles que avaliam nossa produção raramente são imparciais. Somado a isso, internamente, seguimos a tendência de reproduzir sem refletir teorias produzidas em contextos que muito pouco se assemelham ao nosso apenas porque teorias de natureza anglo-saxônica são mais fáceis de legitimar (o famoso estrangeirismo). Em muitos casos, essas teorias se aplicam em parte à nossa realidade, mas, como muitos pesquisadores não adquiriram o conteúdo tácito de lidar com tais teorias de forma que consigam produzir pesquisas cujo formato seja palatável ao público internacional, nossa entrada fica prejudicada.

Por fim, o terceiro problema também levantado pelos colegas aponta o recorrente paroquialismo de nossa academia. Em poucas palavras, ele remete à valorização daquilo que é feito dentro do próprio círculo intelectual em detrimento do que é produzido pelos demais círculos, recorrendo-se a critérios não declarados de julgamento, porém, existentes, que emergem como dogmatismo, preconceito, antagonismo de natureza pessoal, e até perseguição. Alguns desses embates são emblemáticos entre aqueles que defendem posições antagônicas do tipo: quantitativas x qualitativas; ensaístas x empiristas; positivistas x críticos; individualistas metodológicos x estruturalistas; defensores do método científico x anarquistas metodológicos ou pósmodernistas. Minha defesa, aqui, não é de que a academia em Administração apresente um único paradigma, o que seria um equívoco, mas de levantar a possibilidade de ter uma agenda construtiva de debates entre diferentes perspectivas que, ao invés de enfraquecer cada uma das perspectivas, as aprimorem.

\section{Da natureza dos problemas à discussão dos princípios que nos regem}

Tendo em vista os problemas apresentados tanto pelos colegas quanto por mim, finalizo a discussão usando um tom normativo, o que não é comum em textos acadêmicos. Todavia, devido à natureza do fórum e, como já apontei, tendo em vista que estou sendo fiel à perspectiva na qual venho trabalhando, acredito que parte dos problemas por nós vivenciados na academia em Administração brasileira necessariamente nos leva a questionar os princípios pelos quais nossa atividade é construída. Entendo que isso envolve mais do que formar alunos e pesquisadores que sejam especialistas em seu tema, mas que estes sejam inseridos em um conjunto de valores e normas que almeje a integridade do trabalho do pesquisador, especialmente no que diz respeito aos meios pelos quais ele produz. Faz-se, então, apelo à honestidade acadêmica como valor intrínseco à sua atividade, no qual o ato de produzir tem por objetivo o conhecimento e não metas secundárias e até perniciosas. Entre as mais perigosas delas está o fato de apropriar-se do trabalho de outro, independentemente da forma pela qual isso é feito. Por fim, como estamos em uma academia plural, ao invés de acomodarmo-nos ao paroquialismo e ao clientelismo na publicação, deveríamos repensar como nossas diferentes perspectivas podem confrontar-se, acabando com o marasmo que impera em nosso campo, como se houvesse um acordo velado de que a crítica aberta é uma afronta de natureza pessoal. Minha proposta, aqui, que não constitui nenhuma novidade, é de que aceitemos a crítica aberta como critério de objetividade em nossa academia, pois, já que as teorias são falíveis e o método comprovadamente não garante a cientificidade de um empreendimento acadêmico, pelo menos teríamos maior segurança de que a discussão coletiva leva à oxigenação de ideias, produzindo teorias mais plausíveis e refinadas. 
Sobre Desafios Geopolíticos para Pesquisa em Administração

Com o ocaso da Guerra Fria e a ascensão da globalização neoliberal, temos observado nos últimos anos um processo extraordinário e sem precedentes de expansão das fronteiras do conhecimento. Esse processo se caracteriza por três vertentes principais.

A primeira é a transformação sistemática de tudo o que não é conhecimento em conhecimento. Um crescente número de instituições do conhecimento espalhadas pelo mundo vem transformando o não conhecido em conhecimento com base no pressuposto de que o desconhecido ou o que é classificado como não conhecimento não existe ou não deveria existir - em especial os tipos "alternativos" de conhecimento, que são classificados pelas instituições do conhecimento (no singular) como crença ou ideologia. Como um dos resultados desse amplo processo de colonização do(s) mundo(s) e dos "conhecimentos", observa-se não apenas um boom do número de áreas do conhecimento e de temas de pesquisa acadêmica, mas, também, a ascensão do produtivismo acadêmico. Com isso, temos a ilusória sensação de que não há desigualdades ou exclusões.

A segunda é a extraordinária expansão das instituições e organizações que compõem e governam o sistema do conhecimento. Instituições acadêmicas se somam a e concorrem com think tanks, institutos de pesquisa, organizações não governamentais, organizações transnacionais etc. na produção, legitimação e divulgação de conhecimento. No pós-Guerra Fria, as instituições acadêmicas não mais detêm o monopólio ou uma posição privilegiada nesse novo sistema. No início da década passada, e em paralelo às seguidas crises do Consenso de Washington, o Banco Mundial decidiu transformar-se em "banco de conhecimento" ao invés de banco de desenvolvimento e, juntamente com outras instituições transnacionais e um extraordinário número de think tanks, passou a ser um dos mais poderosos produtores, legitimadores, classificadores e difusores de conhecimento (no singular) em escala global. Por sua vez, proliferam organizações e instituições euroamericanas dedicadas a incluir, classificar e divulgar esse conhecimento e, também, as instituições acadêmicas.

A terceira é o processo combinado de desterritorialização e reterritorialização desse sistema do conhecimento. Devido à rápida expansão desse sistema, o não conhecimento e a não inclusão tornaram-se intoleráveis ou inaceitáveis tanto pela direita quanto pela esquerda, tanto pelo Sul global quanto pelo Norte global. A ideia de conhecimento sem fronteiras (quem poderia resistir à sedução de um programa denominado "ciência sem fronteiras"?) proposta pela sociedade do conhecimento defende e promove a inclusão de todos, sem exceção - desde que os diferentes tipos de conhecimento (no plural) sejam convertidos em conhecimento (no singular) pelo sistema dominante do conhecimento - e reforça o argumento colonialista de que não existe e não deve existir nada fora desse sistema. Tendo em vista a institucionalização do pressuposto eurocêntrico de que ficar fora desse sistema de conhecimento significa não existir, parece que não há alternativa para o resto do mundo. Esse quadro "invisível" para nossos olhares destreinados por esse mesmo sistema de conhecimento ajuda a explicar a crescente importância das instituições do conhecimento do Brasil e, também, a crescente preocupação de "nossas" instituições com internacionalização (i.e, euro-americanização) e com rankings e instituições pretensamente universalistas.

Tendo em vista esse contexto de grandes transformações em período de tempo tão curto, não surpreende que a academia de Gestão em diversos países esteja lidando com desafios que não foram previstos ou mesmo imaginados no contexto da Guerra Fria pela maioria de seus constituintes, instituições e stakeholders. A surpreendente ascensão da pesquisa acadêmica em Gestão no contexto da globalização neoliberal tem sido acompanhada por processos de institucionalização em escala global que reproduzem e reforçam o pressuposto questionável de que não existe nada fora desse sistema de conhecimento, que é tido como 
universal - de acordo com os pressupostos do universalismo eurocêntrico. Especialmente no resto do mundo, os avanços da área são mais impostos do que construídos por meio do exercício de autonomia.

Um problema principal é que esses processos são baseados nos conceitos de sociedade do conhecimento e de mundo sem fronteiras estabelecidos pelo neoliberalismo e pela tese do fim da história. Com o advento da globalização neoliberal ocidental e da tese de fim da história (FUKUYAMA, 1989) - em detrimento de outras globalizações, do resto do mundo e de uma enorme variedade de conhecimentos (no plural) que vêm sendo convertidos ou eliminados pelo sistema de conhecimento correspondente - as noções de free market $\mathrm{e}$ free knowledge passaram a permear nosso imaginário e nossas instituições em escala global, apesar de vivermos uma época marcada por evidências e debates que insistem em desafiar tais fundamentos. Segundo um proeminente autor vinculado à terceira via protagonizada por Tony Blair, a globalização significa a expansão sem limite e sem retorno da modernidade eurocêntrica em direção ao resto do mundo (GIDDENS, 1994). Esse quadro ajuda a explicar o enorme número de acadêmicos e instituições da área de Gestão vinculados ao neoliberalismo ocidental e ao americanismo pós-Guerra Fria não apenas no mundo euroamericano, mas, também, no resto do mundo. Por sua vez, esse quadro explica a crescente vinculação ao pós-colonialismo (também majoritariamente eurocêntrico) daqueles que resistem a esse sistema de imposição e sedução por meio de mecanismos ambíguos envolvendo paroquialismo e estrangeirismo e que mantêm excluídas ou invisíveis as dimensões de geopolítica (do conhecimento).

Um segundo problema é que a área de Gestão está mais "blindada" em relação a tais desafios do que algumas outras áreas devido à sua infância e à sua vinculação político-ideológica mais potente com os fundamentos da globalização neoliberal. Mais especificamente, a meteórica trajetória de expansão e institucionalização da academia de Gestão no contexto da globalização neoliberal e dentro do sistema de conhecimento "universal" se soma a outros discursos e processos que ajudam a tornar invisível (i. e., não conhecida) a dimensão da geopolítica do conhecimento (que, por sua vez, foi convenientemente transformada em não conhecimento). Questões (geo)políticas que marcam o contexto de seguidas crises da globalização neoliberal - tais como os eventos de 11 de setembro de 2001 e as invasões do Iraque e do Afeganistão pelo governo George W. Bush, o bloqueio das negociações de Doha pelas economias emergentes em meados da década passada, a crise da ordem neoliberal ocidental iniciada 2008, a crescente importância das economias emergentes em termos econômicos, (geo)políticos e epistêmicos, e a ascensão do sentimento no mundo euro-americano de que o resto do mundo representa uma séria ameaça para a ordem estabelecida - deveriam ter levado a área de Gestão a (re)conhecer a dimensão geopolítica do conhecimento. $\mathrm{O}$ reconhecimento dessas dimensões invisíveis (tidas como não conhecimento pelo sistema dominante de conhecimento) nos ajudaria a entender por que estamos tão comprometidos com o produtivismo e tão seduzidos pela internacionalização. Esses eventos também desafiam a ideia neoliberal de que o apogeu definitivo da modernidade eurocêntrica requer que nos dediquemos todos tão somente à (boa) gestão do mundo ao invés de dedicarmo-nos a construir e a imaginar um mundo em que diversos mundos e conhecimentos podem coexistir (MIGNOLO, 2011). Visto que na sociedade do conhecimento o não conhecido torna-se inexistente e a geopolítica (do conhecimento) é transformada em não conhecimento, essas grandes questões permanecem desconhecidas. Esse quadro de desconhecimento e invisibilidade é de crucial importância para a viabilidade desse sistema eurocêntrico de conhecimento, em detrimento de alternativas.

Esse quadro ajuda a explicar o processo, liderado por EUA e Europa (ex-Primeiro Mundo), de inclusão acelerada ou forçada na área de Gestão dos excluídos (ex-Segundo Mundo) e dos subordinados (ex-Terceiro Mundo) por meio de processos de institucionalização e ranqueamento. Esse processo de acelerada institucionalização em escala global do conhecimento em Gestão foi acompanhado por processos de imposição, vinculados ao Consenso de Washington, e antecedidos por um longo processo de colonialidade iniciado no século XVI com a "descoberta" da América. 
Desde o início dos anos 1990 temos observado um crescente número de pesquisadores de Gestão que criticam os processos de colonização liderados pelos EUA e secundados pela Europa. Um sentimento de antiamericanismo proliferou em décadas recentes, em decorrência da ascensão do unilateralismo dos EUA, das seguidas crises da ordem neoliberal ocidental e da ascensão de economias emergentes. Esse quadro ajuda a explicar o surgimento de novas possibilidades a partir do resto do mundo. Tais opções geoepistêmicas são denominadas "desocidentalização" e descolonização (MIGNOLO, 2011); o surgimento dessas opções tem sido acompanhado de um movimento do tipo "empire strikes back", denominado reocidentalização (Quadro $1)$.

\section{Quadro 1}

Futuros globais e orientações geopolíticas para pesquisa em Gestão

\begin{tabular}{|l|l|}
\hline Orientações & \multicolumn{1}{c|}{ Descrição } \\
\hline Reocidentalização & $\begin{array}{l}\text { O processo tem suas origens nas falhas da invasão do Iraque, na ascensão } \\
\text { do unilateralismo dos EUA e no colapso de Wall Street. Tornou-se projeto } \\
\text { do governo Barack Obama, focado em reparar os prejuízos para a liderança } \\
\text { dos EUA e do Ocidente pelo governo George W. Bush. O principal objetivo } \\
\text { é reconstruir a confiança do mundo nos EUA por meio da mobilização de } \\
\text { três esferas: na da economia, salvar e reimaginar o capitalismo; na da } \\
\text { autoridade, manter a liderança dos EUA no âmbito das relações } \\
\text { internacionais; na do conhecimento, promover ciência e tecnologia com } \\
\text { grandes corporações com a justificativa de revitalizar a economia. }\end{array}$ \\
\hline Desocidentalização & $\begin{array}{l}\text { Teve sua origem no Leste e Sudoeste da Ásia a partir do final dos anos 1990 } \\
\text { e ganhou o suporte da China. Representa, também, um movimento de } \\
\text { desracialização por atores da "raça amarela" que ganhou força quando } \\
\text { China e Índia rejeitaram as instruções de Washington e levaram ao fracasso } \\
\text { da sétima rodada de Doha; tornou-se uma política de economias } \\
\text { emergentes economicamente mais poderosas (China, Singapura, } \\
\text { Indonésia, Brasil, Turquia e, também, Japão). }\end{array}$ \\
\hline Descolonialidade & $\begin{array}{l}\text { Descolonialidade significa a tarefa analítica de revelar a lógica de } \\
\text { colonialidade e a tarefa prospectiva de contribuir com a construção de um } \\
\text { mundo no qual diversos mundos e conhecimentos coexistem; trata-se de } \\
\text { um projeto que define e motiva a emergência de uma sociedade política } \\
\text { global que se desconecta no estágio atual de reocidentalização e } \\
\text { desocidentalização. }\end{array}$ \\
\hline
\end{tabular}

Fonte: Adaptado de Mignolo (2011).

Como resultado, o sistema de conhecimento identificou a permanência de bolsões de não conhecido nas grandes economias emergentes (em especial na China, na Índia, no Brasil e na Rússia). Segundo especialistas em geopolítica, esse não conhecido poderia estar relacionado a não conhecimento (i.e., tradições e ideologias, que são atribuídas a bárbaros e não civilizados) e explicar tanto a ascensão econômica das economias emergentes quanto os riscos correspondentes para a ordem neoliberal ocidental. Isso justifica crescentes investimentos da área de Gestão em reconhecer o não conhecido e mapear e suprimir diferentes tipos de não conhecimento em economias emergentes por meio da mobilização dos mecanismos de produção, inclusão, classificação e publicação liderados pelo Ocidente. 
As áreas de gestão estratégica, gestão internacional e marketing vêm liderando esses processos de reocidentalização e isso ajuda a explicar muitas das recentes transformações verificadas nessas áreas no Brasil. Economias emergentes passaram a ser tidas como instituições acadêmicas e não acadêmicas de Gestão e de outras áreas como uma fronteira a ser explorada e eventualmente contida. Correspondentemente, economias emergentes estão protagonizando grandes processos de reocidentalização e desocidentalização do conhecimento (TSUI, 2009) e isso ajuda a explicar por que estamos cada vez mais comprometidos com o produtivismo acadêmico e a internacionalização. A crescente importância da área de Gestão até para o Partido Comunista Chinês e a acelerada ascensão das instituições acadêmicas de Gestão naquele país e no Brasil, assim como na Índia e África do Sul, ilustram esse fenômeno.

Como acadêmico vinculado há quatro anos à [US] Academy of Management como chair da Divisão de Critical Management, espero que esses movimentos recentes e esse artigo ajudem a tornar menos invisível (mesmo para a blindada área de Gestão) a dimensão da geopolítica do conhecimento. Sob uma perspectiva ampla de geopolítica do conhecimento, entendo que desengajamento não é uma opção. Não devemos trocar a geopolítica do conhecimento pela geopolítica da guerra. Sob uma perspectiva mais realista de "internacionalização", é esperado no Brasil o engajamento da maioria dos acadêmicos com o sistema dominante e com o reocidentalismo. A reocidentalização promove muitas oportunidades sedutoras para pesquisadores e instituições locais. Por um lado, esse quadro restringe as outras duas opções; por outro lado, reforça e justifica as outras duas opções. O avanço agressivo da reocidentalização para contornar as crises da ordem neoliberal ocidental tem resultado no engajamento de crescente quantidade de pesquisadores e instituições de Gestão no Brasil e outros países com a desocidentalização. Por sua vez, a expansão dessas duas opções na academia de Gestão reforça e justifica o engajamento com a descolonialidade.

Portanto, frente ao poderio imperial do reocidentalismo e a obrigação de assumirmos responsabilidades geoepistêmicas mais substantivas, um dos principais desafios para as próximas décadas no Brasil é reconstruir ou reformar as instituições vigentes (Anpad, Capes, CNPq etc.) para que essas três opções tenham o mesmo nível de aceitação, legitimidade e incentivo. Dessa forma, a área de Gestão no Brasil estará em condições de liderar transformações de mesma ordem junto a instituições no exterior (US Academy of Management, Chinese Academy of Management, Banco Mundial, Egos etc.) por meio de um grande projeto que abraça a geopolítica do conhecimento, promove a substituição do universalismo eurocêntrico pela pluriversalidade e possibilita a construção de um mundo no qual diversos mundos e conhecimentos coexistem. Talvez seja pedir ou esperar demais da área de Gestão, mas também pode ser uma excelente oportunidade para reinventarmos a área.

\section{O Estrangulamento da Produção do Conhecimento em Administração no Brasil: Produtivismo, Paroquialismo e Estrangeirismo}

Rafael Alcadipani

A reflexão que proponho em minha intervenção é a respeito dos motivos que levam nossa academia a produzir escritos com tão pouca contribuição teórica e originalidade, como já foi analisado e descrito por tantas revisões e bibliometrias a respeito do nosso campo. Em meu ponto de vista, nossa falta de relevância, rigor e contribuição está associada a três aspectos que são parte constitutiva da pesquisa em Administração no Brasil. Nossos três "pecados" são o produtivismo, o paroquialismo e o estrangeirismo. Discorrerei sobre cada um deles. 


\section{Produtivismo acadêmico}

Produtivismo é a produção de artigos acadêmicos apenas para cumprir quesitos de pontuação acadêmica. É associado a um "fetichismo" do CV Lattes, a querer ver números e mais números de artigos no CV sem se preocupar com o conteúdo do que é escrito. Exemplos são incontáveis. Hoje, alunos de mestrado cursam disciplinas nas quais são obrigados a elaborar artigos, que são submetidos a congressos e, depois, a periódicos. Um artigo deveria ser o produto de uma pesquisa consistente realizada por alguém que domina um campo. Alunos de mestrado, em geral, não têm condições de produzir estudos consistentes, contribuições ao campo. E, o pior, há vários casos de alunos de mestrado da área de operações, por exemplo, que não são apenas obrigados a escrever um artigo sobre finanças, mas, também, publicam esse artigo, mesmo sabendo que jamais irão trabalhar com finanças. Isso também ocorre com os estudantes de doutorado que, submetidos a uma lógica produtivista, escrevem artigos sobre qualquer coisa, em qualquer curso. Publicam textos em áreas nas quais não têm a menor intenção de ser especialistas. Como bem disse o Prof. Celso Antônio Bandeira de Mello, estamos formando uma geração perdida, que não sabe o que é estudar, que não apreende o que é pesquisar de verdade.

Há casos muito piores, pois inúmeros alunos são "convidados" a colocar o nome de seus orientadores em textos que estes não leram uma vez sequer. Em alguns programas de pós-graduação, o simples fato de ser orientador garante a autoria de textos que nunca foram lidos pelo professor. A autoria está sendo totalmente desvirtuada. Andando pelas sessões do Enanpad podemos perceber um dos motivos pelos quais nossa produção acadêmica é tão frágil: ela é majoritariamente realizada por alunos. Percebemos nos periódicos nacionais que raramente um professor publica com outro professor ou sozinho. Nada contra a participação de alunos, que é algo fundamental na formação de bons pesquisadores, mas não é possível alcançar um bom nível quando as discussões acadêmicas são realizadas majoritariamente por pessoas sem a formação necessária para debater. Isso sem falar nos casos em que alunos de pós-graduação acadêmica são forçados a trabalhar em projetos de consultoria de seus orientadores em troca de uma baixa remuneração.

Certa vez, ouvi o seguinte relato:

Quando eu paro para estudar sobre o tema da minha tese, sinto-me, de certa forma, culpada. Sim, parar para ler, reler, entender e tentar fazer um trabalho com substância, embora seja o ideal, algo que se espera de um doutorando, põe-me frágil nesse sistema porque sei que enquanto estou dedicando-me outros estão publicando e preocupando-se apenas com a quantidade de publicações. E se, após o doutorado, no momento de buscar um emprego, geralmente o que vai valer é apenas a quantidade, como, então, tentar ser sério e produzir pesquisas com contribuições relevantes sob uma lógica dessas?

Já argumentei que o produtivismo existe porque ele é útil. Ele é útil para inúmeros professores que podem continuar na pós-graduação sem fazer pesquisa, sem ir a campo, sem fazer entrevistas, sem rodar modelos, pois deixam o que deveria ser trabalho seu nas mãos de estudantes para assumir cargos de prestígio e poder ou para poder ganhar dinheiro com consultoria e com educação executiva. O problema disso é que muitos de nós estamos transformando nossos alunos em proletários da pós-graduação. Há alguns meses, um amigo, aluno de pós-graduação, disse-me que não encontra no Brasil um modelo de pesquisador para admirar. Isso é muito grave. $\mathrm{O}$ que nos falta é valorizar a carreira de pesquisador dando verdadeiros incentivos para as pessoas se dedicarem à pesquisa. Vale lembrar, também, inúmeros programas de pós-graduação nos quais alunos trabalham 40 horas por semana em seus empregos e ainda fazem mestrado ou doutorado. Estamos esquecendo que a formação de um bom aluno, de um bom pesquisador, exige dedicação quase integral aos estudos. Para isso, temos de pensar em formas de financiar estudantes para, de fato, estudar.

Como existe uma enxurrada de artigos, ao invés de barrarmos as produções acadêmicas inconsistentes estamos criando cada vez mais periódicos. Uma grande parte dos periódicos nacionais funciona com o 
simples objetivo de escoar produção acadêmica sem qualidade. Pouquíssimos de nossos periódicos têm qualidade, pouquíssimos deles têm um processo editorial rigoroso, pouquíssimos deles possuem cartas de decisão editorial. É urgente rever a política de classificar periódicos apenas por indexadores e outros tipos de métricas, ainda mais quando a área de Administração classifica como seus periódicos da Veterinária, da Engenharia Agrícola, da Odontologia, da Enfermagem, da Nutrição, e de tantas outras áreas. Há casos de periódicos no Qualis da Administração que são flagrantemente de outras áreas do conhecimento que não só classificamos como nossos, mas atribuímos uma avaliação maior do que a própria área. Assim, fica, mesmo, difícil sermos levados a sério como área do conhecimento. Precisamos avaliar a qualidade do que se publica nos periódicos e a qualidade dos processos de decisão editorial para que um texto seja publicado. Porém, não é apenas o produtivismo que nos assola. O paroquialismo também contribui para os problemas de nossa academia.

\section{Paroquialismo}

O paroquialismo é outra de nossas vicissitudes. Em algumas áreas e em algumas cabeças do campo há uma grande preocupação em "preservar o que é nosso", com uma hipervalorização do que é nacional. Percebemos no campo alguns Policarpos Quaresma. Não quero ser pretensioso, muito menos arrogante ou mal-educado, mas existe uma tendência em algumas esquinas acadêmicas de valorizar excessivamente autores nacionais pelo simples fato de serem nacionais. Vejamos o exemplo do Guerreiro Ramos. Um grande intelectual para seu tempo, que trouxe avanços significativos para a área e que ajudou a pensar o Brasil de sua época. Porém, utilizar suas ideias sem uma contextualização para o Brasil de hoje é agir contra seu pensamento e é ser incapaz de refletir a respeito de questões contemporâneas. A obra de muitos autores brasileiros do campo é datada, assim como muitas de nossas obras serão datadas. Pensadores cujas ideias permanecem são raros e poucos. E, mesmo nesses casos, é preciso ter cuidado. Inúmeros estudos sobre cultura brasileira em Administração, onde clássicos nacionais como Sérgio Buarque de Hollanda e Gilberto Freyre são utilizados para discutir cultura brasileira em organizações de hoje são escritos sem se levar em conta nuances de nossa contemporaneidade. Aliás, autores como Jesse de Souza já discutiram vários dos mitos inerentes e propalados pelos clássicos de nosso país que servem para a construção da inferioridade de alguns grupos sociais perante outros. É fundamental ler e prestigiar os clássicos e os autores brasileiros, mas também é fundamental contextualizar suas ideias, algo que o pensamento paroquial muitas vezes deixa de lado.

Agora, um dos principais problemas do paroquialismo é que o discurso da defesa do nacional serve, muitas vezes, para manter as coisas como estão e não mudar nada. Não podemos aceitar que o discurso paroquial ajude a perpetuar as mazelas do produtivismo, como tem acontecido hoje, que o paroquialismo faça com que textos sem qualidade sejam escritos e publicados apenas por ser produzidos por brasileiros, que periódicos nacionais de baixa qualidade e rigor perpetuem-se.

Em algumas situações, o critério do julgamento de qualidade paroquial é se certo texto vem de um autor brasileiro ou estrangeiro, esquecendo-se de que a grande maioria dos autores em Administração no Brasil copia acriticamente autores estrangeiros. A imensa maioria dos estudos em Administração no Brasil, principalmente em áreas como estudos organizacionais e ensino e pesquisa, é constituída por ensaios teóricos focada em autores Europeus. Em outras áreas, como estratégia e operações, trata-se da aplicação de modelos gerados em outro contexto econômico de forma simples e simplória. Parece que uma grande parcela dos estudiosos do campo tem horror a ir a campo e, quando o fazem, produzem textos com metodologia fraca e inconsistente. Ser atento ao nacional é ir à "realidade" brasileira, estudar a "realidade" brasileira, conhecer a "realidade" brasileira, com referências que possibilitem à realidade se expressar em sua complexidade e não ser tolhida e escondida atrás de teorias e modelos. Estudamos muito pouco a Administração no Brasil. Um dos motivos de nossa falta de originalidade deve-se ao fato de olharmos muito pouco para a nossa realidade, 
para o que acontece no Brasil. Porém, o paroquialismo de alguns setores é compensado pelo estrangeirismo de outros.

\section{Estrangeirismo}

Temos uma tendência de supervalorizar o estrangeiro; trata-se de um histórico em nosso país originado em nosso passado colonial. Hoje, o ensino e a pesquisa de Administração é um negócio global e milionário. A indústria de livros, de periódicos e de ensino em Administração gera receitas estupendas e não podemos ser inocentes nesse cenário. Faculdades, universidades, editoras e tantos outros tipos de organização lutam nesse mercado. E não podemos fechar os olhos para o fato de que os norte-americanos e os europeus possuem uma agenda expansionista, principalmente em um cenário de crise econômica no Norte do mundo. Muitas das conversas de intercâmbio proposta pelos "gringos" são nada mais, nada menos do que uma forma de atrair recursos para seus países. Muitas universidades e faculdades de países do Norte dependem, em larga medida, dos recursos provenientes de alunos do Terceiro Mundo. Valorizar o ensino e a pesquisa do Norte como de "primeira linha" é fundamental para a construção de nossa inferioridade como pesquisadores, implica deixar para eles o papel de criar modelos e refletir e posiciona-nos como meros reprodutores.

Mais importante do que isso, é preciso ter em mente que muito do mercado de publicações acadêmicas, tido como "internacional", é controlado por editoras anglo-saxãs e por acadêmicos anglo-saxões. Se pegarmos aqueles que são tidos como os principais periódicos da área, quase que apenas são publicados artigos de temáticas específicas produzidos em universidades específicas. Publicar em um periódico internacional envolve trabalho acadêmico sério, mas também envolve questões de poder. Vejo, hoje, muitos acadêmicos de diferentes partes do mundo procurando um "broker" anglo-saxão para que seus artigos possam ser publicados nos tais periódicos de renome. Com isso, privilegia-se o gringo superior e permanece nossa condição de subalternos. Muitos dos gingos acreditam, de fato, que somos inferiores. Conheço inúmeros casos: de um colega que não pode usar dados originados por brasileiros em sua tese desenvolvida na Inglaterra pelo fato de seu orientador acreditar que gestores brasileiros não possuem cognição a um professor estrangeiro que perguntou em uma aula para alunos de doutorado em minha escola se eles tinham ouvido falar de um francês chamado Michel Foucault.

Além disso, quando a Academy of Management organiza uma conferência na África, como ocorreu recentemente, ela o faz para atrair pessoas daquela região e reforçar sua forma de pensar o conhecimento em Administração como superior, para reforçar sua hegemonia. Quando a Organization Science organiza um workshop de desenvolvimento de artigos na Bocconi, na Itália, ela reforça sua forma de produzir conhecimento em Administração como a melhor forma de fazê-lo isso, como a forma mais "legítima" e "internacional" de fazê-lo. O pensamento anglo-saxão é predominante no campo, e isso está relacionado a uma política de Estado dos EUA durante a Guerra Fria, como minhas pesquisas mais recentes indicam. O que é preciso destacar é que existe um pensamento hegemônico no campo, principalmente de origem norteamericana, que tende a desconsiderar perspectivas qualitativas e abordagens mais reflexivas. Ser norteamericano não significa seguir essa visão restrita e restritiva da pesquisa no campo. Há norte-americanos que defendem uma visão mais plural, assim como temos latinos que defendem uma visão mais restritiva de pesquisa no campo. O que percebo é um choque internacional entre as visões. Na França, por exemplo, temos escolas que optam por uma visão mais ampla, como a Paris Duphine, e que optam por uma visão mais restrita, como a Insead, chamada por alguns franceses de EuroDisney. Há, ainda, os acadêmicos do Terceiro Mundo que desenvolveram sua formação sob a visão mais limitada e tentam impor tal perspectiva em seus países em nome do "rigor" e da "relevância", que caracterizam os pensadores mais reflexivos como "obscuros". 
Nosso campo, acredito, encontra-se estrangulado pelas inter-relações entre o produtivismo, o paroquialismo e o estrangeirismo. Precisamos, então, pensar em como produzir conhecimento em Administração procurando desenvolver pesquisas sérias, fugindo da armadilha de produzir por produzir, evitando o paroquialismo, mas, por outro lado, evitando a adoração não refletida ao que vem de fora. Devemos, claro, participar do debate internacional, mas não como subalternos de uma visão de mundo. O que precisamos é formar alunos que sejam capazes de pensar com sua própria cabeça e que sejam capazes de realizar pesquisa de qualidade.

\section{Internacionalização da Produção em Administração: Lidando com a Rejeição e Tocando em Frente}

\section{Sandro Cabral}

Em que pesem as frequentes e, na maior parte das vezes, justas reclamações relacionadas aos baixos salários pagos e à estrutura inadequada para o desenvolvimento das atividades, muitos indivíduos acabam atraídos pela carreira acadêmica. De fato, a liberdade intelectual, a flexibilidade dos horários, a possibilidade de realizar atividades que fogem da rotina, o aprendizado decorrente da interação com alunos, acadêmicos de diversas regiões e nacionalidades, apenas para citar alguns fatores, fazem com que a atividade de ensino e pesquisa seja bastante sedutora.

No entanto, todos nós que enveredamos pelos caminhos da produção de artigos científicos invariavelmente deparamo-nos com as dificuldades inerentes à publicação em veículos de maior impacto, sobretudo quando escolhemos divulgar nossos produtos em periódicos internacionais de ponta. Os esforços são hercúleos e passam pela escolha de um tema relevante, pela identificação de uma lacuna na literatura, pela descoberta da linguagem adequada para dialogar com a comunidade escolhida, pelo rigor empregado nas análises e, por fim, pelo conhecimento dos ritos caros ao processo de submissão, revisão e interação junto a editores, revisores anônimos e coautores nacionais e internacionais. Evidentemente, esse processo não é isento de percalços e frustações oriundos de pareceres que, não raro, expõem as fragilidades de nossos trabalhos, e por consequência, nossas deficiências enquanto pesquisadores.

Nesse diapasão, a rejeição de artigos ao longo do processo de avaliação sempre desperta polêmicas. Normalmente, os primeiros dias após a recusa de um artigo não são nada agradáveis. Sensações de raiva, depressão e angústia emergem e tendem a ser amplificadas quando se trata de rejeições em journals internacionais, dado o esforço realizado ex ante e dada a expectativa gerada durante o período de avaliação, quando aguardamos o retorno dos editores e pareceristas. ${ }^{8}$ Nesse momento, habitualmente, xingamos os editores e pareceristas de imperialistas, dizendo que ignoram as teorias e conteúdos produzidos em países em desenvolvimento. Baixada a adrenalina, deparamo-nos com dois possíveis padrões de comportamento: (a) desistir e publicar o artigo em uma revista nacional, convictos de que o mundo lá fora parece ignorar teorias produzidas a partir da realidade brasileira; ou (b) trabalhar arduamente na reformatação do artigo e enviar a outro periódico internacional de ponta, nesse caso acreditando que o mundo lá fora parece estar ávido por boas teorias produzidas de forma metodologicamente consistente e, sobretudo, a partir de bases de dados únicas, não importando o país de origem.

Ambas as escolhas indicadas são válidas, afinal, o bem supremo da vida acadêmica é (ou deveria ser) a liberdade intelectual. Porém, por razões de foco, abordemos a segunda alternativa. Apesar de todos os

\footnotetext{
8 Tal situação se aplica também quando recebemos um Revise and Resubmit (R\&R) com sugestões de mudanças substanciais que, não raro, exigem uma nova coleta de dados ou a reestruturação completa do artigo.
} 
esforços relacionados a uma publicação internacional de qualidade, muitos dos que escolhem esse caminho são vistos com reserva por parte expressiva dos colegas nacionais por ser supostamente subservientes a uma tradição de pesquisa não brasileira e ao uso do inglês em suas peças. Tendo como premissas que o estabelecimento de um processo de comunicação normalmente demanda a emissão, a recepção, a interpretação e o retorno em relação à mensagem originalmente enviada e que uma linguagem comum auxilia a mediação dessa relação, ao que aparenta, a língua inglesa parece ser necessária caso queiramos fazer-nos ouvir, interferir no debate internacional e partir da posição de compradores para a de fornecedores de teorias para uma audiência internacional ampla, pelo menos enquanto o esperanto não se consolida como língua universal ou o português não passa a ser dominado por anglo-saxões, árabes, orientais, hindus, eslavos e africanos (CABRAL e LAZZARINI, 2011).

Em verdade, acredito que o esforço de internacionalização reforça a construção da soberania da academia nacional, que não precisa e não deve ser renegada ou deixada de lado em nossas publicações internacionais. Com efeito, há diversos exemplos de trabalhos produzidos por acadêmicos brasileiros da área de Administração publicados em diversos veículos internacionais de alto impacto, com temáticas nacionais e com dados locais, sem qualquer auxílio de despachantes acadêmicos anglo-saxões (usando um termo cunhado pelo professor e amigo Rafael Alcadipani), longe de qualquer deslumbramento em relação ao que vem do estrangeiro e que, sem dúvida, contribuem para enfatizar para um público internacional as competências de nossos pesquisadores.

A audiência internacional é ampla, há espaço para publicar nossos achados em periódicos dos mais diversos matizes, de revistas pertencentes ao mainstream a journals com linhas editoriais mais heterodoxas. O próprio encontro anual da Academy of Management é um grande mosaico das várias correntes e possibilidades existentes, abarcando, por exemplo, áreas funcionais da Administração, grupos de orientação crítica e adeptos do estudo da espiritualidade nas organizações com sessões de meditação intercaladas entre os painéis nos quais os artigos sobre o tema são apresentados. Tudo é uma questão de procurar o público com quem se quer dialogar e realizar os esforços para ser ouvido e influenciar no debate, sem que entremos na cantilena do discurso ingênuo de que ao empreender esforços para internacionalizar em linguagem compreendida pela maioria do mundo acadêmico estaríamos perpetuando uma estrutura de dominação. Sendo bem honestos, quando reclamamos do preconceito por parte do centro (leia-se Estados Unidos e Europa Ocidental) em relação à periferia (nós), olvidamo-nos de que essa mesma argumentação é frequentemente proferida por acadêmicos de regiões fora do eixo Centro-Sul e por vários pesquisadores brasileiros que julgam que não conseguem publicar nas próprias revistas nacionais por não ser conhecidos pelos editores de periódicos. Não se trata, aqui, de tentar julgar a pertinência desses argumentos, uma vez que não se sabe o que pode ser associado à discriminação efetiva ou a mera autodefesa de quem não empreendeu ou não quer empreender os esforços necessários à produção de um produto acadêmico provido de rigor e, sobretudo, relevância. Isso seria uma discussão estéril. Entretanto, é preciso colocar tais fatos em perspectiva para que possamos ter maior clareza dos acontecimentos que nos circundam, para que façamos nossas escolhas ponderando todos os aspectos envolvidos e para que tenhamos a real dimensão de nossos atos.

Outro ponto a ser tratado é a questão do produtivismo e seus impactos sobre a relevância do que é publicado. É fato que os sistemas de medição de desempenho de pesquisadores lastreados na publicação de artigos em periódicos contribuíram para uma elevação da publicação do que é realizado dentro das torres de marfim nacionais, o que, em si, é positivo. Entretanto, é inegável que os mecanismos de recompensa (e punição) associados à publicação (ou não) de artigos em periódicos têm gerado uma série de comportamentos desviantes, desde a produção de peças de baixíssima relevância, passando pela emersão de coautorias espúrias, pelas pressões exercidas junto a editores de periódicos, pelo envio simultâneo do mesmo artigo a vários periódicos, em um flagrante desrespeito ao escasso tempo dos avaliadores, chegando, por fim, à clonagem de artigos. Para além do autoplágio, um dos pecadinhos mais comuns na academia, um ponto que precisa ser tratado com seriedade é a tradução para outras línguas de artigos em português já publicados no Brasil, visando à sua publicação em veículos no exterior. Nesse caso, a busca pela maximização de 
"pontinhos Capes" pode colocar em xeque um princípio basilar dos periódicos científicos: o ineditismo dos artigos publicados, gerando consequências negativas para a comunidade acadêmica, principalmente em relação ao quesito credibilidade.

Por fim, se, por um lado, a internacionalização da produção em Administração é tarefa árdua que, em muitos momentos, exige renúncia às várias coisas que valorizamos em nossas vidas, por outro, proporciona júbilos pessoais e externalidades positivas para nossos programas de pós-graduação e para a própria consolidação da academia brasileira no cenário mundial. De minha parte, por enquanto, estou convicto de que a luta vale a pena, em que pesem as inerentes rejeições, ora justas, ora injustas, que virão pela frente.

\section{Referências}

CABRAL, S.; LAZZARINI, S. G. Internacionalizar é preciso, produzir por produzir não é preciso. Organizações \& Sociedade, v. 18, n. 58, p. 541-542, 2011.

FUKUYAMA, F. The end of history. The National Interest, v. 16, p. 3-18, 1989.

GIDDENS, A. Beyond left and right: the future of radical politics. Stanford: Stanford University Press, 1994.

KUHN, T. S. A estrutura das revoluções científicas. 9. ed. São Paulo: Perspectiva, 2009.

LAKATOS, I. Falsificação e metodologia dos programas de investigação científica. Lisboa: Ed. 70, 1978.

MERTON, R. K. The ethos of science. In: MERTON, R. K. On social structure and science. Chicago: The University of Chicago Press, 1996. p. 267-276.

MIGNOLO, W. The darker side of Western modernity: global futures, decolonial options. London: Duke University Press, 2011.

TSUI, A. Autonomy of inquiry: shaping the future of emerging scientific communities. Management and Organization Review, v. 5, n. 1, p. 1-14, 2009. 